\title{
Equity implications of rice fortification: a modelling study from Nepal
}

\author{
Naomi M Saville ${ }^{1,2, *} \oplus$, Macharaja Maharian ${ }^{1}$, Dharma S Manandhar ${ }^{3}$ and \\ Helen A Harris-Fry 4 \\ 'UN World Food Programme, Kathmandu, Nepal: ${ }^{2}$ Institute for Global Health, University College London, London, \\ WCIN 1EH, UK: ${ }^{3}$ Mother and Infant Research Activities (MIRA), Kathmandu, Nepal: ${ }^{4}$ London School of Hygiene and \\ Tropical Medicine, WC1E 7HT, London, UK
}

Submitted 13 September 2019: Final revision received 8 March 2020: Accepted 17 March 2020: First published online 6 July 2020

\begin{abstract}
Objective: To model the potential impact and equity impact of fortifying rice on nutritional adequacy of different subpopulations in Nepal.

Design: Using 24-h dietary recall data and a household consumption survey, we estimated: rice intakes; probability of adequacy (PA) of eight micronutrients commonly fortified in rice (vitamin $A$, niacin $\left(B_{3}\right)$, pyridoxine $\left(B_{6}\right)$, cobalamin $\left(B_{12}\right)$, thiamin $\left(\mathrm{B}_{1}\right)$, folate $\left(\mathrm{B}_{9}\right)$, Fe and $\mathrm{Zn}$ ) plus riboflavin $\left(\mathrm{B}_{2}\right)$, vitamin $\mathrm{C}$ and $\mathrm{Ca}$ and mean probability of adequacy (MPA) of these micronutrients. We modelled: no fortification; fortification of purchased rice, averaged across all households and in rice-buying households only. We compared adequacy increases between population subgroups.

Setting: (i) Dhanusha and Mahottari districts of Nepal (24-h recall) and (ii) all agroecological zones of Nepal (consumption data).

Participants: (i) Pregnant women ( $n$ 128), mothers-in-law and male household heads; (ii) households ( $n$ 4360).

Results: Unfortified diets were especially inadequate in vitamins $\mathrm{B}_{12}, \mathrm{~A}, \mathrm{~B}_{9}, \mathrm{Zn}$ and Fe. Fortification of purchased rice in rice-purchasing households increased $\mathrm{PA}>0.9$ for thiamin, niacin, $\mathrm{B}_{6}$, folate and $\mathrm{Zn}$, but $\mathrm{B}_{12}$ and $\mathrm{Fe}$ remained inadequate even after fortification (PA range 0.3-0.9). Pregnant women's increases exceeded men's for thiamin, niacin, $\mathrm{B}_{6}$, folate and MPA; men had larger gains in vitamin A, $\mathrm{B}_{12}$ and $\mathrm{Zn}$. Adequacy improved more in the hills (coefficient 0.08 (95\% CI 0.05, $0 \cdot 10)$ ) and mountains (coefficient $0.07(95 \%$ CI 0.01, 0.14)) but less in rural areas (coefficient -0.05 (95\% CI $-0.09,-0.01)$ ).

Conclusions: Consumption of purchased fortified rice improves adequacy and gender equity of nutrient intake, especially in non-rice-growing areas.
\end{abstract}

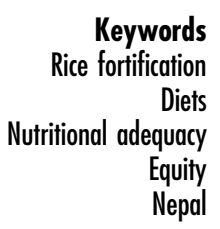

Women's diets are deficient in multiple micronutrients across many low-income settings ${ }^{(1)}$, and these deficiencies have negative effects throughout the life course. Before and during pregnancy, inadequate micronutrient intake adversely affects the risk of maternal mortality, offspring's fetal growth and birth weight ${ }^{(2,3)}$. Despite political commitments to address malnutrition, at least two billion people suffer from micronutrient deficiencies globally ${ }^{(4)}$.

Nepal Demographic Health Surveys estimate that anaemia has risen to $41 \%$ in women of reproductive age in recent years. This is particularly concerning because anaemia is a major cause of maternal mortality ${ }^{(5)}$. Beyond anaemia, deficiencies of multiple micronutrients are prevalent in Nepal and exist concurrently. Amongst pregnant women in the Terai, Jiang et al. ${ }^{(6)}$ found micronutrient deficiencies to be common, including vitamins A (7\%), E (25\%), D (14\%), riboflavin $(33 \%)$, vitamin $\mathrm{B}_{6}(40 \%), \mathrm{B}_{12}(28 \%)$, folate (12\%), Zn (61\%) and Fe (40\%). The 2016 Nepal National Micronutrient Status Survey reported low ferritin in $27.6 \%$ of children aged $6-59$ months, $18.7 \%$ of non-pregnant and $14.2 \%$ of pregnant women ${ }^{(7)}$. Meanwhile, $\mathrm{Zn}$ and vitamin A deficiencies were detected in 20.7 and $4.2 \%$ of children aged $6-59$ months and 24.3 and $3 \%$ of nonpregnant women, respectively ${ }^{(7)}$.

Limited dietary data from Nepal indicate that diets fail to provide adequate nutrients ${ }^{(8,9)}$. In rural mountainous areas, 
$34 \%$ of people were both food poor (unable to access sufficient energy) and nutrient poor (unable to access sufficient micronutrients), while $24 \%$ were nutrient poor only ${ }^{(10)}$. Across Nepal, rice is consumed daily, in large quantities ${ }^{(8,11)}$, and forms the major source of micronutrients $^{(9,11)}$. Realistic dietary recommendations based on locally available foods may be insufficient to meet nutritional gaps ${ }^{(12)}$, and food-insecure households are unlikely to achieve nutritional adequacy by this means in the short term $^{(13,14)}$

Fortification of rice in Asia has emerged as a means to improve nutritional adequacy ${ }^{(15-20)}$. In Bangladesh, fortification of rice through social safety nets is having very positive results $^{(21)}$. In Cambodia, fortified rice school meals had positive effects on cognition ${ }^{(22)}$ and micronutrient status ${ }^{(23)}$, although effects were limited by inflammation ${ }^{(24)}$. Fe fortification of rice decreased anaemia significantly amongst school children in Bangalore ${ }^{(25)}$, Andhra Pradesh ${ }^{(26)}$, Odisha $^{(27)}$ Brazil $^{(28,29)}$ and the Philippines ${ }^{(30)}$ and factory workers in Mexico ${ }^{(31)}$. In Costa Rica, mandatory rice fortification, together with other fortification efforts, was associated with decreased anaemia, $\mathrm{B}_{9}$ (folate) deficiency and neural tube defects ${ }^{(31,32)}$.

With this in mind, rice fortification in Nepal has been identified as a potential strategy to reduce micronutrient deficiencies. It can deliver micronutrients safely and cheaply, builds on existing infrastructure and requires minimal behavioural change ${ }^{(18,33)}$. The Government of Nepal, in partnership with the UN World Food Programme (WFP), intends to introduce fortified rice via Nepal Food Corporation (NFC) social safety nets in remote and foodinsecure districts, by establishing blending units in NFC rice mills. Later, introduction of blending technology to private sector mills will enable wider distribution of fortified rice. However, Nepalese rice intakes, dietary nutrient deficiencies and the potential for rice fortification to address them have not been explored. Whilst increased adequacy of fortified nutrients is expected with fortification, measurement of potential differential impacts in population subgroups is needed to examine who will benefit most from rice fortification in Nepal. Moreover, whilst some studies have modelled the micronutrient contribution of fortified foods, they have failed to account for total dietary intake ${ }^{(34)}$. Thus, in the current study, we model the potential impacts of rice fortification on nutritional adequacy of the entire diet of different population subgroups to investigate the equity impact and inform rice fortification in Nepal.

\section{Methods}

Between June and September 2015, we collected individual 24-h dietary recalls of pregnant women, their mothers-in-law and male household heads, in Dhanusha and Mahottari districts in province $2^{(35-39)}$, as part of the Low Birth Weight South Asia Trial (LBWSAT) ${ }^{(40,41)}$. Between
19 September 2014 and 16 July 2015, the third Nepal Annual Household Survey (AHS III) estimated 7-d household food consumption for a nationally representative sample of households ${ }^{(42)}$. These two studies provide rich data to estimate the potentially differential benefits of rice fortification in different population subgroups. Using LBWSAT individual-level dietary data, we can precisely model the potential impacts of rice fortification and estimate the intra-household equity implications of rice fortification in province 2, where underweight and anaemia are highest ${ }^{(43)}$. Using AHS III data provides a national picture of consumption and enables us to model potential rice fortification impacts on adults and children, and in different geographies.

\section{Sampling and field procedures}

The LBWSAT protocol ${ }^{(40,44)}$ and dietary measures 35,36$)$ have been described elsewhere. Whilst 24-h dietary recalls were collected in 805 households in eighty Village Development Committee clusters overall, we use data from 128 households sampled in the twenty control clusters. Within each traditional joint, male-headed household sampled, dietary recalls were taken with the pregnant woman, her mother-in-law and male household head. Recalls were repeated up to three times per person on non-consecutive days within a period of 2 weeks ${ }^{(35,36)}$. Portion sizes were estimated using a pictorial food atlas of portion sizes that was developed and validated locally ${ }^{(36)}$.

The AHS III sampled fifteen households in each of 288 primary sampling units that were selected using population proportional to size from 4861 urban and 36191 rural enumeration areas. Selected primary sampling units covered sixty-five of the seventy-five districts in Nepal and thus may be considered to be nationally representative, covering all agro-ecological zones and wealth groups. Using 2011 household census lists, 4360 households were randomly selected for interview. After describing the household composition using a roster, respondents were interviewed about their consumption of a list of foods and drinks, yielding a dataset with the details of consumption of sixty foods. If an item was consumed in the preceding week, enumerators recorded the frequency $(\mathrm{d} /$ week) and quantity $(\mathrm{kg} /$ week from home production, purchase or receipt in-kind) that the item was consumed ${ }^{(42)}$.

\section{Analysis of dietary data}

In both datasets, we calculated the proportion of households consuming rice and purchased rice, mean rice consumption $(\mathrm{g} / \mathrm{d})$ for each household member. With the AHS III, we calculated mean intake of purchased rice and used adult male equivalents (AME) ${ }^{(45)}$ to allocate household-level intakes to individuals. We calculated average daily nutrient intakes using nutrient composition values from a Nepal-specific food composition table (FCT) (available on request) ${ }^{(36)}$. 
We estimated nutritional adequacy of eight micronutrients normally recommended for rice fortification ${ }^{(46)}$ : vitamins $\mathrm{A}, \mathrm{B}_{3}$ (niacin), $\mathrm{B}_{6}$ (pyridoxine), $\mathrm{B}_{12}$ (cobalamin), $\mathrm{B}_{1}$ (thiamin), $\mathrm{B}_{9}$ (folate), Fe and $\mathrm{Zn}$, plus three other micronutrients: $\mathrm{Ca}, \mathrm{B}_{2}$ (riboflavin) and vitamin $\mathrm{C}$. Then, by substituting micronutrient values of unfortified rice with the WFP 2016 fortified rice specification ${ }^{(47)}$, we quantified the potential increase from rice fortification in probability of adequacy (PA) for each nutrient, mean probability of adequacy (MPA) of eleven nutrients and equity of nutrient adequacy.

Table 1 provides the nutrient levels in unfortified uncooked rice, the estimated levels of water-soluble $\mathrm{B}$ vitamins in unfortified cooked rice after applying a conversion factor of $1 / 0.36=2.78$ for deriving dry weight, the $\mathrm{WFP}^{(47)}$ and Bangladesh ${ }^{(48)}$ fortified rice specifications and those recommended by DePee et al. ${ }^{(49)}$. Despite evidence of nutrient losses during washing and cooking of milled rice ${ }^{(50)}$, we were not able to access estimates of losses in the Nepal context, where cooking method varies by region. Hence, we used uncooked rice nutrient estimates, since the $\mathrm{Nepal}^{(51)}$ and India ${ }^{(52)}$ FCT provide only uncooked rice, and FCT vary widely in their rice estimates. Also, AHS III estimated dry uncooked rice consumption only, so introducing conversions to cooked rice would have introduced further error. Table 1 shows the figures used for uncooked rice and two alternative estimates of water-soluble $\mathrm{B}$ vitamins in cooked rice (converted to the dry weight) from figures in the Bangladesh ${ }^{(53)}$ and United States Department Agriculture ${ }^{(54)}$ FCT. For $\mathrm{B}_{6}$ and $\mathrm{B}_{3}$, our raw rice estimates lie in the estimates of cooked rice from United States Department Agriculture and Bangladesh FCT, whereas for $\mathrm{B}_{1}, \mathrm{~B}_{2}$ and $\mathrm{B}_{9}$, the cooked values are somewhat lower than those for raw rice.

Since only purchased rice is going to be fortifiable in the foreseeable future, we modelled fortification of purchased rice only, not home-grown rice. For LBWSAT, we estimated the purchased share of rice based on ranking (1-5) of the importance of purchasing as their main rice source, assuming that the ranking was proportional $(1=100 \%$ of rice bought; $2=80 \%$ bought, and so on).

PA was calculated using the 'probability approach'(55). For LBWSAT, we estimated daily 'usual' intakes by transforming nutrient intakes to normal distributions using Box-Cox transformations ${ }^{(56)}$ and calculating the best linear unbiased predictors to account for within- and betweenperson variance. For AHS III, daily usual intakes were simply 1/7 of weekly intakes. For both datasets, we calculated PA by comparing intakes (apart from Fe for non-pregnant women) with known nutrient requirement means (estimated average requirements (EAR)) and $\mathrm{SD}^{(57-60)}$. We assumed low bioavailability of $\mathrm{Fe}$ (at $5 \%$, apart from pregnant women at $23 \%)^{(57)}$ and $\mathrm{Zn}$ (18\% men; $25 \%$ women; $23 \%$ children $)^{(61)}$. When unavailable, we calculated EAR for all age groups and pregnancy status using reference nutrient intakes for each nutrient as follows: $\mathrm{EAR}=$ reference nutrient intake $\times$ $((2 \times \mathrm{CV} / 100)+1)$, and $\mathrm{SD}$ as EAR $\times \mathrm{CV}$. We used US Institute of Medicine values for $\mathrm{Ca}(\mathrm{EAR} \text { and } \mathrm{SD})^{(58)}$ and $\mathrm{Fe}$ $(\mathrm{PA})^{(59)}$. For $\mathrm{Zn}$, we used EAR from the IZiNCG study ${ }^{(61)}$, and for all other nutrients, we used FAO/WHO 2004 values $^{(57)}$ based on estimates of CV from WHO $2006^{(62)}$.

\section{Sensitivity analyses}

As a sensitivity analysis of different fortificant blends, we repeated these analyses using the Bangladesh fortified rice standard. We did not model the Indian standard as this is unlikely to be used in Nepal due to its riboflavin content, which affects colour, flavour and acceptability ${ }^{(63)}$. As LBWSAT data were collected during mango season, we report vitamin A intakes with and without mangos. AHS III data were missing green leafy vegetables and eggs, so we conducted a sensitivity analysis with a daily $50 \mathrm{~g}$ portion of green leafy vegetables, and one egg added to the diet.

Since the AHS III analyses rely on AME to estimate individual intakes, we used LBWSAT data to measure the agreement between observed and predicted intakes for pregnant women, their mothers-in-laws and male household heads with and without adjustments for pregnancy, physical activity levels and body weight. The BlandAltman limits of agreement were calculated as the mean $\mathrm{kJ}$ difference between observed and predicted intakes (SD 1.96) ${ }^{(64)}$.

We also calculated the percentage whose micronutrient intake exceeded upper tolerable limits of the fortifiable nutrients ${ }^{(57)}$.

\section{Equity analyses}

To estimate the potential gender equity impact of fortification in LBWSAT, we calculated the increase in PA from fortification for pregnant women and men and differences between the two (difference in difference). Then, we tested whether the intercept of this difference in difference was significantly different from zero using linear regression models. To estimate the differential impact of fortification by regions in AHS III, we applied doublehurdle regressions (Cragg's models) which account for the large number of zeros for people who have no fortification because they are home producers. The models assess the probability of benefiting from fortification in two equations (i) whether or not households have any improvements in MPA (determined by whether they purchase any rice) and (ii) how much the MPA improved (determined by how much purchased rice is consumed). We report the conditional mean estimates of the mean difference in PA comparing all other provinces with province 3 (where Kathmandu is based), hills and mountains with Terai and rural with urban areas. All analyses and reported 


\section{Public Health Nutrition}

Table 1 Micronutrient levels in unfortified uncooked rice and in dry weight of cooked rice from various sources

\begin{tabular}{|c|c|c|c|c|c|c|c|c|c|c|c|}
\hline \multirow[t]{7}{*}{ Vitamin } & \multirow{2}{*}{$\begin{array}{l}\text { Parameters } \\
\text { Energy }\end{array}$} & \multirow{2}{*}{$\frac{\text { Unit }}{\mathrm{kJ}}$} & \multirow{2}{*}{$\begin{array}{c}\begin{array}{c}\text { Per } 100 \mathrm{~g} \\
\text { uncooked } \\
\text { rice }\end{array} \\
1443\end{array}$} & \multirow{2}{*}{$\begin{array}{l}\text { FCT } \\
\text { Nepal }\end{array}$} & \multicolumn{2}{|c|}{$\begin{array}{c}\text { Bangladesh estimates: } \\
\text { water-soluble } \\
\text { B vitamins } / 100 \mathrm{~g} \text { dry } \\
\text { weight }^{*}\end{array}$} & \multicolumn{2}{|c|}{$\begin{array}{l}\text { USDA estimates: } \\
\text { water-soluble } \\
\text { B vitamins } / 100 \mathrm{~g} \text { dry } \\
\text { weight }^{\star}\end{array}$} & \multirow[t]{2}{*}{$\begin{array}{l}\text { WFP } \\
\text { standard: } \\
\text { fortified } \\
\text { uncooked } \\
\text { rice† }\end{array}$} & \multirow[t]{2}{*}{$\begin{array}{l}\text { Bangladesh* } \\
\text { standard: } \\
\text { fortified } \\
\text { uncooked riceł }\end{array}$} & $\begin{array}{l}\text { de Pee et al. }{ }^{(49)} \\
\text { recommendation: } \\
\text { fortified uncooked } \\
\text { rice§ }\end{array}$ \\
\hline & & & & & & & & & & & \\
\hline & Protein & $\mathrm{g}$ & $6 \cdot 8$ & Nepal & & & & & & & \\
\hline & $\mathrm{Ca}$ & $\mathrm{mg}$ & 10 & Nepal & & & & & & & \\
\hline & $\mathrm{Se}$ & $\mathrm{mcg}$ & 1.01 & India & & & & & & & \\
\hline & $\mathrm{Zn}$ & $\mathrm{mg}$ & 1.21 & India & & & & & 6.5 & 4.0 & $6 \cdot 0$ \\
\hline & $\mathrm{Fe}$ & $\mathrm{mg}$ & 0.7 & Nepal & & & & & 4.5 & $6 \cdot 0$ & $4 \cdot 0$ \\
\hline A & Vitamin A & $\mathrm{RE}(\mathrm{mcg})$ & 0 & India & & & & & 175 & 183 & 150 \\
\hline $\mathrm{B}_{1}$ & Thiamin & $\mathrm{mg}$ & 0.21 & Nepal & $0.03 \times 2.78=$ & 0.08 & $0.02 \times 2.78=$ & 0.06 & 0.75 & 0.5 & 0.5 \\
\hline $\mathrm{B}_{2}$ & Riboflavin & $\mathrm{mg}$ & 0.06 & Nepal & $0.01 \times 2.78=$ & 0.03 & $0.01 \times 2.78=$ & 0.03 & & & \\
\hline$B_{3}$ & Niacin & $\mathrm{mg}$ & 1.9 & Nepal & $1.1 \times 2.78=$ & 3.06 & $0.04 \times 2.78=$ & 0.11 & 8.5 & 0 & $7 \cdot 0$ \\
\hline $\mathrm{B}_{6}$ & Pyridoxine & $\mathrm{mg}$ & 0.12 & India & $0.03 \times 2.78=$ & 0.08 & $0.09 \times 2.78=$ & 0.25 & 0.9 & 0 & 0.6 \\
\hline \multirow{2}{*}{$\mathrm{B}_{9}$} & Folate & $\mathrm{mcg}$ & $9 \cdot 32$ & India & $3 \times 2.78=$ & $8 \cdot 34$ & $3 \times 2.78=$ & 8.34 & 317 & 267 & \\
\hline & Folic acid & $\mathrm{mcg}$ & & & & & & & 190 & 160 & 130 \\
\hline $\mathrm{B}_{12}$ & Cobalamin & $\mathrm{mcg}$ & 0 & India & No info & No info & 0 & 0 & 1.5 & $1 \cdot 2$ & 1.0 \\
\hline $\mathrm{C}$ & Ascorbic acid & $\mathrm{mg}$ & 0 & India & & & & & & & \\
\hline $\mathrm{E}$ & $\alpha$-Tocopherol & $\mathrm{mg}$ & 0.06 & India & & & & & & & \\
\hline
\end{tabular}

FCT, Food Composition Table; WFP, World Food Programme; USDA, United States Department Agriculture; RE, retinol equivalents. *The conversion factor for weight of uncooked to cooked rice is 0.36 making the conversion from cooked rice to dry rice $1 / 36=0.278$. †WFP 2016 specification based on mid-point between minimum and maximum levels leaving factory.

$\ddagger$ Bangladesh estimates are for the household level after losses from storage.

§For population consuming $150-300 \mathrm{~g} / \mathrm{d}^{(49)}$. 
SE account for survey design and were conducted in Stata SE 14 (StataCorp LP).

\section{Results}

\section{Response rate and respondent characteristics}

The LBWSAT sample included 150 households out of 199 eligible households visited, and we modelled potential effects of rice fortification on 128 households (1230 dietary recalls from 384 individuals) because twenty-two households had missing information on rice purchase. Prior analyses show characteristics of respondents and nonrespondents were similar ${ }^{(38)}$. AHS III data contain 4360 households with 5443 women aged 15-49years and 3346 children aged 5-12 years.

Characteristics of the households are given in Table 2.

In both LBWSAT and AHS III samples, women and men are poorly educated. Pregnant women from LBWSAT are younger (median age 21 years), and mothers-in-law are older ( 50 years) than the women of reproductive age in the AHS III sample (28 years). Nearly half of LBWSAT households have members working overseas, and perceived food insecurity and thinness (mid-upper arm circumference $<23 \mathrm{~cm})^{(65,66)}$ are prevalent, the latter particularly amongst pregnant women. Diets lack diversity with $38-42 \%$ consuming fewer than the recommended five out of ten food groups on the 1 st day of recall ${ }^{(67)}$.

\section{Rice intakes}

The LBWSAT plains population (see online supplementary material, Supplemental Table 1) and AHS III Nepal-wide (Fig. 1) intake data show that rice is consumed regularly, by most people, and in high quantities, making it a promising candidate for fortification.

In LBWSAT, boiled white rice made up the majority of the diet. Almost all (98\%) households ate rice over the $3 \mathrm{~d}$ of dietary recall, and $76 \%$ purchased it. Respondents consumed rice 1.8 times/d amounting to a median cooked weight of $667 \mathrm{~g} / \mathrm{d}$. Fried rice, rice pudding, porridge ('khichadi' or 'jaulo'), beaten rice, puffed rice or as an ingredient in deep-fried snacks were occasionally consumed, but the mean frequencies of consumption (range 0.01$0 \cdot 10$ times/d) were much lower than boiled rice. Wheat, consumed as an unleavened bread called 'roti', and 'dal' (lentil soup) were both consumed on average once per day.

Consistent with LBWSAT results, $99 \%$ of AHS III households consumed rice in the preceding week (Fig. 1).

Per capita daily uncooked rice consumption was lower than LBWSAT figures, at mean 314(SD 170) g/d and 149 (SD 186) g/d of purchased rice. Whilst overall rice consumption was highest in the Terai province 2 (where LBWSAT was located), the results indicate that the mountains and urban areas would benefit most from fortification, since the consumption of purchased rice was highest in these provinces (provinces 6, 5, 3 and 1).

\section{Current micronutrient intakes and adequacy}

In both samples, micronutrient intakes before fortification ('current' rows in Table 3) show diets are low in key micronutrients. Despite the different methods of estimation, micronutrient intakes were reasonably similar between LBWSAT and AHS III, although intakes were lower in AHS (see Table 3 'current'). In LBWSAT, nutrient intakes were highest amongst men, followed by pregnant women, and mothers-in-law ate least.

The micronutrients that are consumed in particularly low levels are those that are not found in unfortified rice. Dehulled, non-parboiled, non-fortified rice provides no vitamins $A$ or $B_{12}$, very little of vitamins $B_{1}$ (thiamin), $B_{2}$ (riboflavin), $\mathrm{Fe}, \mathrm{Zn}$, vitamin $\mathrm{B}_{6}$ (pyridoxine) and somewhat higher levels of $\mathrm{B}_{9}$ (folate) and $\mathrm{B}_{3}$ (niacin) (see Table 1 and de Pee ${ }^{(46)}$ ). Our sensitivity analysis of adding a daily portion of $50 \mathrm{~g}$ green leafy vegetables and one egg to AHS estimates generated intakes more similar to LBWSAT. Vitamin $\mathrm{B}_{12}$ intakes were close to zero for all subgroups.

The PA in the unfortified diets is shown in the 'current' bars in Fig. 2 (AHS III) and Fig. 3 (LBWSAT).

Across both samples, diets with unfortified rice are highly deficient in multiple micronutrients, notably vitamins $\mathrm{B}_{12}, \mathrm{~B}_{9}$ (folate) and $\mathrm{A}, \mathrm{Fe}$ and $\mathrm{Zn}$ for all household members studied. In the unfortified diets of pregnant women, only vitamins $\mathrm{B}_{3}$ (niacin), $\mathrm{B}_{6}$ (pyridoxine) and $\mathrm{B}_{1}$ (thiamin) exceeded $50 \% \mathrm{PA}$, while vitamins $\mathrm{A}, \mathrm{B}_{9}$ (folate), Fe and $\mathrm{Zn}$ all lie below $10 \% \mathrm{PA}$ and vitamin $\mathrm{B}_{12}$ has a PA approaching zero (Fig. 3). Whilst deficiencies in the diet are less extreme for male household heads and mothers-in-law, PA below $30 \%$ are found for vitamin A, $\mathrm{Fe}, \mathrm{Zn}$, and PA for vitamin $\mathrm{B}_{12}$ is, again, close to zero. Similarly, unfortified AHS diets are highly deficient in vitamins $\mathrm{B}_{12}, \mathrm{~A}, \mathrm{~B}_{9}$ (folate) and $\mathrm{Fe}$.

\section{Potential micronutrient intakes and adequacy after rice fortification}

All population subgroups analysed show large increases in micronutrient intakes after fortification, with much higher increases when only rice-purchasing households are analysed. Table 3 provides daily nutrient intakes when all purchased rice in the diets is fortified, averaged across all households (labelled 'Fortified (all)') and in ricepurchasing households (labelled 'Fortified (buyers)'). This shows how potential effects will be constrained by households who do not purchase rice and therefore do not benefit from fortification. Fortification with the Bangladesh standard premix (see online supplementary material, Supplemental Table 2) leads to broadly similar, although slightly lower, intakes than consumption of the WFP standard except for $\mathrm{B}_{3}$ (niacin) and $\mathrm{B}_{6}$ (pyridoxine), which are not in the Bangladesh standard. 


\section{Nes Public Health Nutrition}

Table 2 Socio-demographic and health characteristics of the samples

\begin{tabular}{|c|c|c|c|c|c|c|c|}
\hline \multicolumn{4}{|l|}{ LBWSAT } & \multicolumn{4}{|c|}{ National AHS III* } \\
\hline & $n$ & $\begin{array}{l}\text { Mediant, } \\
\text { mean‡ or \% }\end{array}$ & 25th, 75 th centile & & $n$ & $\begin{array}{l}\text { Mediant, } \\
\text { mean‡ or \% }\end{array}$ & $\begin{array}{l}\text { 25th, 75th percentiles } \\
\text { or (SE) }\end{array}$ \\
\hline Age & & & & Age & & & \\
\hline Pregnant women $†$ & 150 & 21 & 19,24 & Women $15-49$ years & 5443 & 28 & 21,36 \\
\hline Mothers-in-law† & 150 & 50 & 44,56 & Children $5-12$ years & 3346 & 9 & 7,11 \\
\hline Male $\mathrm{HH}$ headst & 150 & 39 & 25,56 & & & & \\
\hline Caste group & 150 & & & & & & \\
\hline Disadvantaged§ & & $35 \cdot 3 \%$ & & & & & \\
\hline Middle\| & & $42.7 \%$ & & & & & \\
\hline Least disadvantagedๆ & & $22.0 \%$ & & & & & \\
\hline Maternal education & 150 & & & Maternal education & & & \\
\hline No schooling & & $56.1 \%$ & & Ability to read (\%) & 4360 & $49.6 \%$ & \\
\hline Primary class $1-8$ & & $27.0 \%$ & & Education grade & 4360 & 3.4 & $(0.2)$ \\
\hline Secondary class 9 and above & & $16.9 \%$ & & & & & \\
\hline Male education & 147 & & & Male education & & & \\
\hline No schooling & & $42.2 \%$ & & Ability to read (\%) & 4360 & $68.6 \%$ & \\
\hline Primary class 1 to 8 & & $29.9 \%$ & & Education grade & 4360 & & $(0 \cdot 1)$ \\
\hline Secondary class 9 and above & & $27.9 \%$ & & & & & \\
\hline Overseas migration & 128 & & & & & & \\
\hline Any household member & & $46.1 \%$ & & & & & \\
\hline Household Food Insecurity Access Scale & 134 & & & & & & \\
\hline Any food insecurity ${ }^{\star *}$ & & $30.6 \%$ & & & & & \\
\hline Minimum dietary diversity $\dagger \dagger$ & 150 & & & & & & \\
\hline Pregnant women & & $58.0 \%$ & & & & & \\
\hline Mothers-in-law & & $59.3 \%$ & & & & & \\
\hline Male HH heads & & $62.0 \%$ & & & & & \\
\hline Low mid-upper arm circumference $(<23 \mathrm{~cm})$ & 150 & & & & & & \\
\hline Pregnant women & & $40.0 \%$ & & & & & \\
\hline Mothers-in-law & & $35.3 \%$ & & & & & \\
\hline Male $\mathrm{HH}$ heads & & $14.0 \%$ & & & & & \\
\hline
\end{tabular}

AHS III, the third Nepal Annual Household Survey; LBWSAT, Low Birth Weight South Asia Trial; Male HH heads, male household heads.

*Estimates after applying sampling weights.

¥Mean and SE.

tMean and SE.

§Disadvantaged. Dalit and Muslim.

MMiddle: Janjati/lother Terai castes.

१(Least disadvantaged. Yadav, Brahmin.

t+Adequate dietary diversity $\geq 5$ out of ten food groups. 


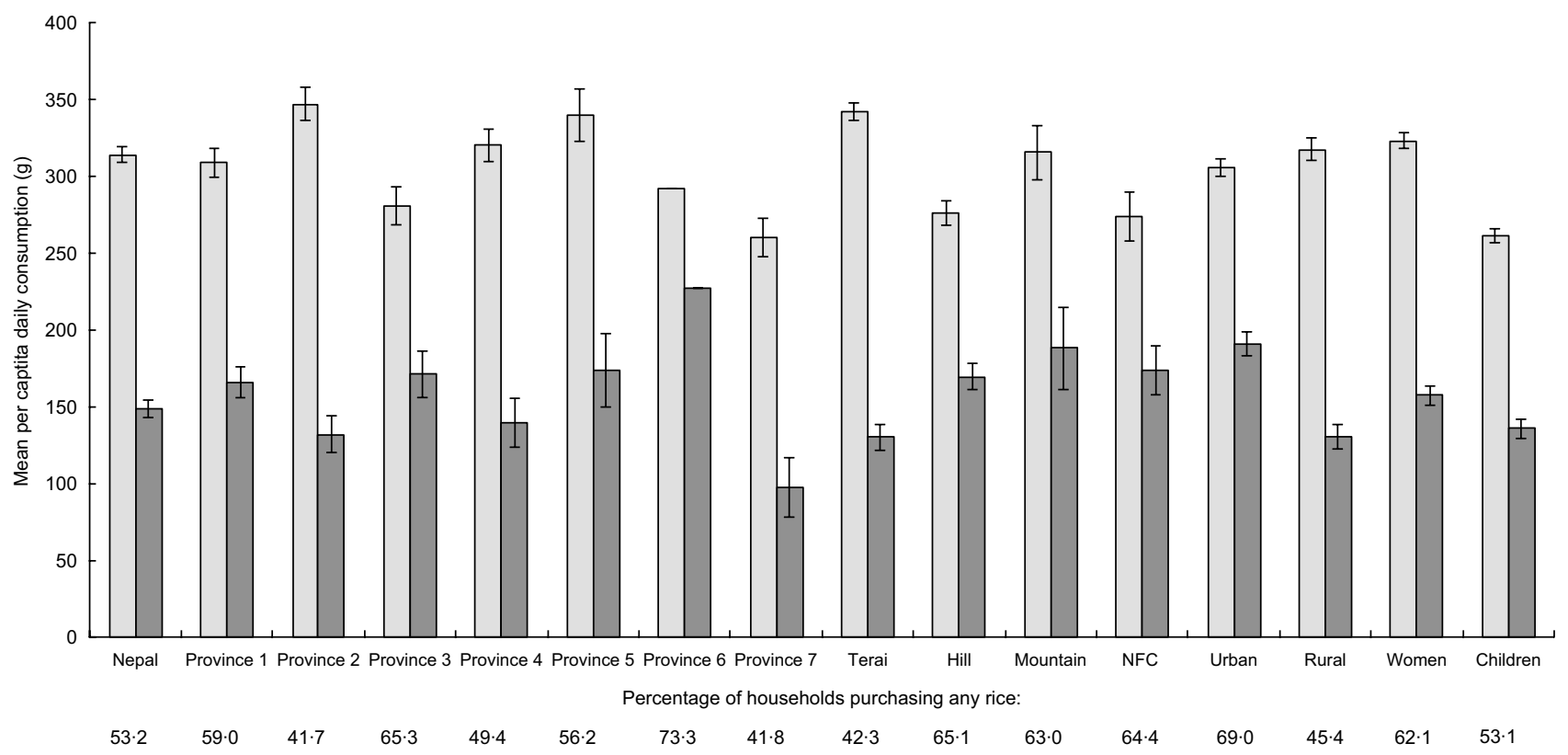

Fig. 1 Mean intakes of all rice and purchased rice by province, ecological zone, rural/urban, women and children. Using Annual Household Survey 2014-15 data. Percentage of households purchasing rice is provided below each category. $\square$, rice from all sources (purchased, grown, received); $\square$, purchased rice only (potential for fortification). NFC, Nepal Food Corporation

The PA in the 'current', 'Fortified (all)' and 'Fortified (buyers)' diets is given for AHS women and children (Fig. 2) and LBWSAT household members (Fig. 3). After substituting normal rice with fortified rice using fortificant levels in the 2016 WFP specifications, dietary deficiencies of key nutrients are largely resolved in rice-purchasing households. Smaller but nevertheless substantial improvements in mean adequacy levels are found when non-rice purchasing households (who would not access fortified rice) are included in the population average. Amongst rice purchasers in all population subgroups, PA exceeded $90 \%$ for $\mathrm{B}_{3}$ (niacin), $\mathrm{B}_{6}$ (pyridoxine), $\mathrm{B}_{1}$ (thiamin), $\mathrm{B}_{9}$ (folate) and $\mathrm{Zn}$ after fortification. Vitamin $\mathrm{A}$ increased to $>85 \%$ PA for AHS women, male household heads and mothers-in-laws but was lower for pregnant women and children. After fortification of rice, the mean PA of Fe did not reach $100 \%$ for any household member category. The impact of fortified rice on Fe adequacy was lowest for mothers-in-law, reflecting their lower rice consumption than other family members. However, if we assume that Fe bioavailability is higher due to the presence of fortified rice in the diet (15\% rather than $5 \%$ ), we see much larger increases in Fe PA on average in the full AHS sample (women $77 \%$; children $87 \%$ ) and especially in rice-buying AHS households (women 95\%; children $99 \%$ ).

Increases in MPA with fortification of rice were constrained by deficient nutrients that are not included in the fortificant premix such as $\mathrm{Ca}$, vitamins $\mathrm{B}_{2}$ (riboflavin) and $\mathrm{C}$. In rice-purchasing households, MPA increased by around 30 percentage points (pp) for all groups, to around $70 \%$ for women and children and $80 \%$ for men.
We assessed risk of exceeding upper tolerable intake levels (UL) and found no issues. We however noted that, to avoid exceeding UL for niacin, niacinamide will need to be used (as required by the WFP specification) in fortification because it has a much higher UL $(900 \mathrm{mg} / \mathrm{d})$ than nicotinic acid $(35 \mathrm{mg} / \mathrm{d})$. However, for populations reliant on groundwater such as those in the Terai, our estimates of Fe adequacy are uncertain due to the wide variance in estimates of Fe concentrations in groundwater in Nepal ${ }^{(68-71)}$. Sensitivity analyses of adding the lowest estimate of $0.04 \mathrm{mg} / \mathrm{d}^{(70)}$ and a water intake of $21 / \mathrm{d}^{(72)}$ would result in almost zero change in PA estimates. Adding a very high estimate $(42 \mathrm{mg} / \mathrm{d})$ as found in Bangladesh ${ }^{(73)}$ would result in a PA from water intakes alone of 1 for pregnant women, men and women if $15 \%$ bioavailability is assumed. With $5 \%$ bioavailability, all pregnant women and men would have an Fe PA of 1 and non-pregnant women a PA of $>0.85$.

The risk of exceeding UL of Fe would be high if consuming $42 \mathrm{mg} / \mathrm{d}$ from water, since the upper level cut-off is $45 \mathrm{mg} / \mathrm{d}$. However, the probability of such high intakes is low, since Nepal estimates include $0.05-10.81 \mathrm{mg} / 1$ (eastern Terai $\left.{ }^{(68)}\right), 0.3$ to $19.5 \mathrm{mg} / \mathrm{l}$ (central Terai ${ }^{(71)}$ ) and 0.02 to $1.9 \mathrm{mg} / \mathrm{L}^{(69,70)}$ (Kathmandu valley). Therefore, although Fe contamination of water is more likely in the Terai, more rice is grown so people are less likely to consume fortified rice in this region. Nevertheless, monitoring of Fe contamination, water intakes and serum ferritin levels may need to accompany implementation of rice fortification programmes going forward.

Analysis of the impact of fortification on gender equity (Fig. 4) shows that women benefit from fortification relatively more than men. 
Increases in adequacy were significantly higher in women than in men for vitamins $\mathrm{B}_{9}$ (folate) (41pp; $P<0.001), \mathrm{B}_{3}$ (niacin) (23pp; $\left.P<0.001\right), \mathrm{B}_{6}$ (pyridoxine) (14pp; $P<0.001), \mathrm{B}_{1}$ (thiamin) (8pp; $\left.P<0.01\right)$ and overall MPA ( $2 \mathrm{pp} ; P<0.05$ ), whereas for vitamins $\mathrm{A}, \mathrm{B}_{12}$ and $\mathrm{Zn}$, increases were significantly higher for men $(25,14$ and 18 pp respectively), and increase in Fe adequacy was similar.

Regional differences in potential impact of fortification are shown in Table 4.

We find minimal differences across provinces, but significantly larger improvements in MPA in hills (8pp; $P<0.001)$ and mountains (7pp higher; $P<0.05)$ than the plains and 5pp $(P<0.05)$ lower improvements in rural than urban areas.

Our test of agreement between observed intakes and intakes predicted by the application of AME (see online supplementary material, Supplemental Table 3) indicates that the application of AME does not result in large bias (range -351 to $276 \mathrm{~kJ}$ ) but does overestimate pregnant women's intakes, underestimate men's intakes and gives wide limits of agreement. This overestimation is greatly increased if AME account for pregnancy status. Incorporation of self-reported activity levels to adjust AME also does not appear to increase agreement between observed and predicted intakes.

\section{Discussion}

This is the first study to model the potential effects of rice fortification on probability of micronutrient adequacy and to examine its equity implications. We find that Nepalese unfortified diets are inadequate, and rice is consumed in high quantities, making rice suitable for fortification. Nutrient inadequacy is high for vitamins $\mathrm{B}_{12}, \mathrm{~A}, \mathrm{~B}_{9}$ (folate), $\mathrm{Fe}$ and $\mathrm{Zn}$ (all potentially fortifiable in rice) and also $\mathrm{Ca}$ and riboflavin. Different geographical areas are likely to benefit differentially from rice fortification, depending upon where purchased rice consumption is highest (remote province 6 , the mountains and urban areas). Perhaps unsurprisingly, we find that replacing normal purchased dehulled, notparboiled polished white rice with fortified rice (as per the mid-point between minimum and maximum WFP specifications) would resolve dietary deficiencies in ricepurchasing households amongst all population subgroups analysed for all fortified micronutrients, except vitamin $\mathrm{B}_{12}$ and $\mathrm{Fe}$ in pregnant women (if higher bioavailability is assumed). However, the equity implications are arguably more interesting and important. Rice fortification is predicted to increase pregnant women's adequacies more than adult males for most nutrients. Due to higher intakes of bought rice, the nutritional adequacies of more remote hilly and mountainous populations are predicted to improve more in response to rice fortification than in the plains, as will adequacy in urban compared with rural areas. 

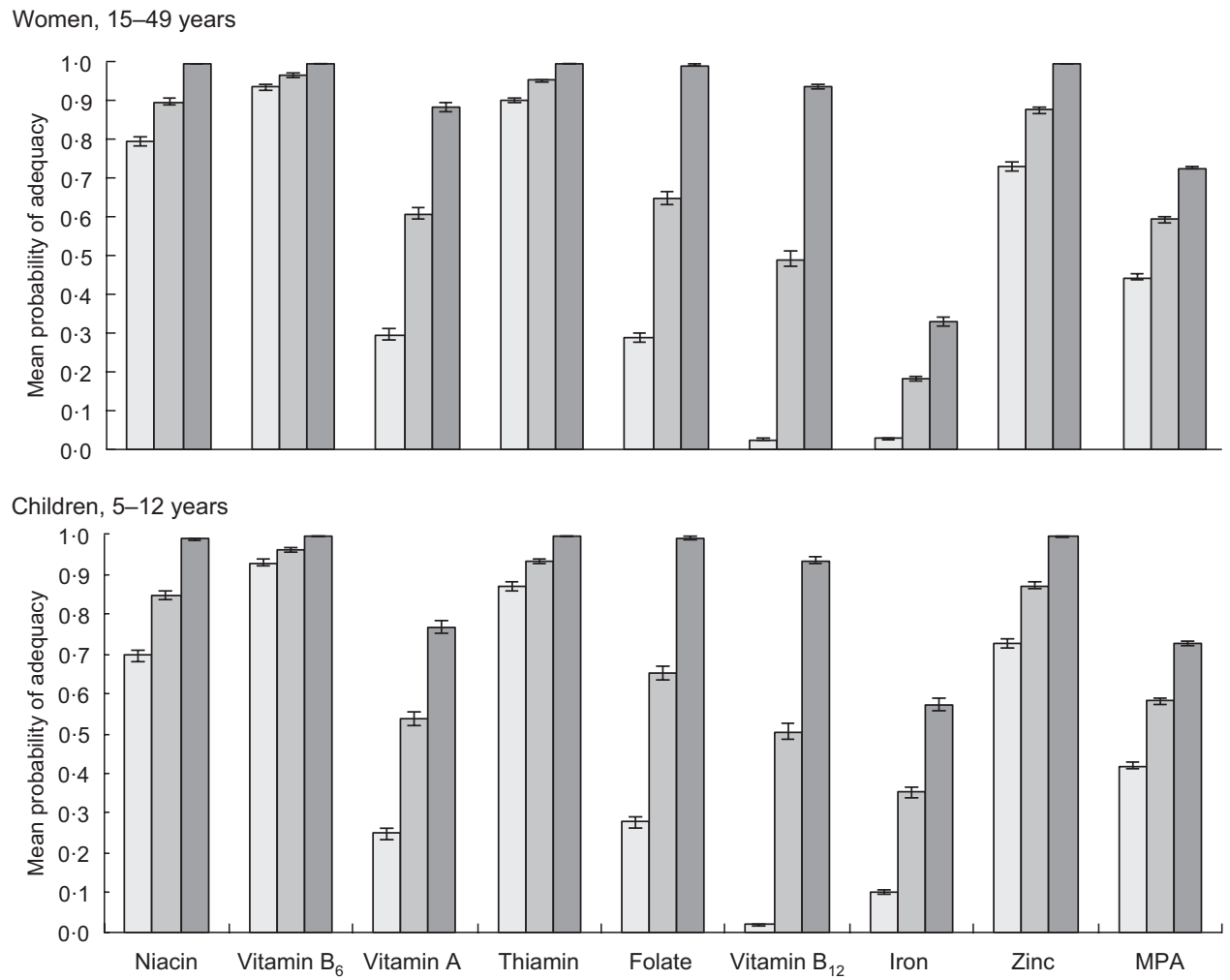

Fig. 2 Probability of micronutrient adequacy of women and children in Nepal, with and without rice fortification. Using Annual Household Survey 2014-15 data. Current: based on unfortified diets of total population (women $n$ 5443; children $n$ 3346). Fortified (all): based on total population when bought rice is fortified with World Food Programme (WFP) mid-point values (women $n$ 5443; children $n$ 3346). Fortified (buyers): based on intakes of rice-buying households only, when bought rice is fortified with WFP mid-point values (women $n$ 3007; children $n$ 1882). $\square$, current; $\square$, full sample; $\square$, buyers only. MPA, mean probability of adequacy

\section{Implications for addressing micronutrient deficiencies}

Our results indicate that WFP 2016 specification levels for rice fortification are generally appropriate and could address major nutrient gaps, although we could consider reducing levels of $\mathrm{B}_{3}$ (niacin), which is already found in rice. For a location where rice consumption is $150-300 \mathrm{~g} /$ capita per d, de Pee ${ }^{(46)}$ and de Pee et al. ${ }^{(49)}$ recommended the following fortification levels: $\mathrm{Fe}$ (micronised ferric pyrophosphate), $7 \mathrm{mg} / 100 \mathrm{~g}$ (or if ferric pyrophosphate is combined with citrate and trisodium citrate, or possibly other solubilising agents $4 \mathrm{mg} / 100 \mathrm{~g}$ ); folic acid $\left(\mathrm{B}_{9}\right) 0 \cdot 13$ $\mathrm{mg} / 100 \mathrm{~g}$; vitamin $\mathrm{B}_{12}$ (cyanocobalamin) 0.001 mg/100 g; vitamin A (palmitate) $0.15 \mathrm{mg} / 100 \mathrm{~g} ; \mathrm{Zn}$ (oxide) $6 \mathrm{mg} /$ $100 \mathrm{~g} ; \mathrm{B}_{1}$ (thiamine mononitrate) $0.5 \mathrm{mg} / 100 \mathrm{~g} ; \mathrm{B}_{3}$ (niacin amide) $7 \mathrm{mg} / 100 \mathrm{~g}$ and $\mathrm{B}_{6}$ (pyridoxine hydrocloride) $0.6 \mathrm{mg} / 100 \mathrm{~g}$. The WFP 2018 updated recommendation provides corresponding increases/decreases per $100 \mathrm{~g}$ with decreasing/increasing levels of rice consumption ${ }^{(49)}$. We found that the 2016 median WFP specification we tested broadly matched these new recommendations but had slightly elevated levels of most micronutrients.

For pregnant women, additional Fe and Vitamin $\mathrm{B}_{12}$ from improved dietary quality and supplements would still be required to reach adequacy. Since the Nepal government distributes free Fe/folic acid supplements for $225 \mathrm{~d}$ of pregnancy and early lactation, the shortfall in these micronutrients should be met amongst pregnant and lactating women who consume these supplements sufficiently. However, vitamin $\mathrm{B}_{12}$, which is only found in animalsource foods, appears to be a problem nutrient, especially in the plains.

Although riboflavin $\left(\mathrm{B}_{2}\right)$ intakes are inadequate, we do not suggest adding riboflavin to the Nepal fortificant premix, due to colour changes in the fortified rice kernels which reduce consumer acceptability ${ }^{(63)}$. Whilst levels of fortificants recommended in fortified rice are safe, caution has been advised due to an association between fortified rice consumption and hookworm infection ${ }^{(74)}$. Promotion of fortified rice, especially in schools, needs to be accompanied with deworming and public awareness campaigns promoting the use of footwear and other hygiene and sanitation practices.

Micronutrient deficiencies in the Nepalese diet we investigated are similar to those found in mothers and young children in Bangladesh, although vitamins $\mathrm{A}, \mathrm{B}_{9}$ (folate) and $\mathrm{Zn}$ deficiencies were worse and vitamin $\mathrm{B}_{12}$ less severe in Bangladesh ${ }^{(75)}$. Our estimates suggest higher 

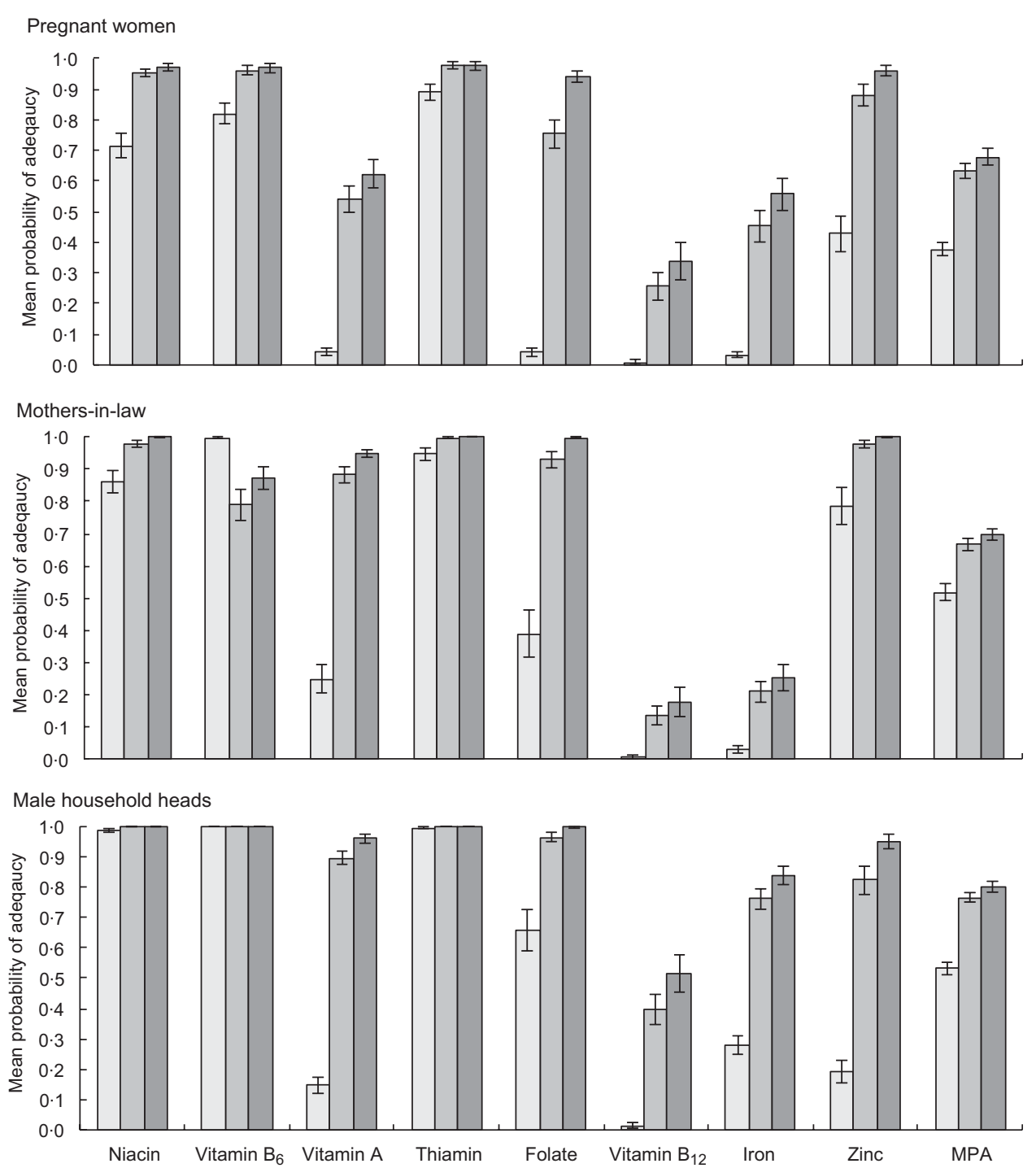

Fig. 3 Probability of micronutrient adequacy of pregnant women, their mothers-in-law and male household head in Nepal province 2 , with and without rice fortification. From Low Birth Weight South Asia Trial data. Current: based on unfortified diets of all respondents ( $n$ 128); Fortified (all): based on intakes of all respondents when bought rice is fortified with World Food Programme (WFP) mid-point values ( $n$ 128); Fortified (buyers): based on intakes of rice-buying households only, when bought rice is fortified with WFP mid-point values ( $n$ 97). $\square$, current; $\square$, full sample; $\square$, buyers only. MPA, mean probability of adequacy

adequacy in pregnant women and other population subgroups in 2015 than those found for lactating mothers in urban Nepal in $2009^{(9)}$. Nevertheless, the diets we studied are severely deficient, and staple fortification is warranted.

One study applied a similar modelling approach to ours using UK dietary consumption data. They simulated vitamin D fortification of wheat flour and milk and analysed the effect upon adequacy of intake amongst at-risk population subgroups. When wheat flour was fortified, the proportion estimated to have vitamin $\mathrm{D}$ intakes below reference nutrient intakes fell from 93 to $50 \%$ without any individual exceeding UL ${ }^{(76)}$. In Vietnam, Laillou et al. ${ }^{(77)}$ similarly used data from a national survey of women's diets to estimate the impact of different fortified foods upon dietary intake. Rice fortified with $\mathrm{Fe}, \mathrm{Zn}$ and folic acid increased intakes as a percentage of the reference nutrient intake by $41 \%$ for $\mathrm{Fe}, 16 \%$ for $\mathrm{Zn}$ and $34 \%$ for $\mathrm{B}_{9}$ (folate), making fortified rice the most appropriate fortification vehicle in that setting ${ }^{(77)}$. In 2013, a Fortification Assessment Coverage Toolkit was designed to help stakeholders collect, analyse and synthesise standardised data on quality, coverage and consumption of fortified foods. By assessing amounts of fortifiable and fortified foods consumed, 'feasibility gaps' and 'fortification 'gaps' can be quantified to estimate the potential of different fortified foods and the extent it is being fulfilled ${ }^{(34)}$. The limitation in this method is that it ignores other (nonfortified) dietary sources, a problem which is rectified in our approach.

The potential clinical significance of the increases in micronutrient adequacy that could result from the 


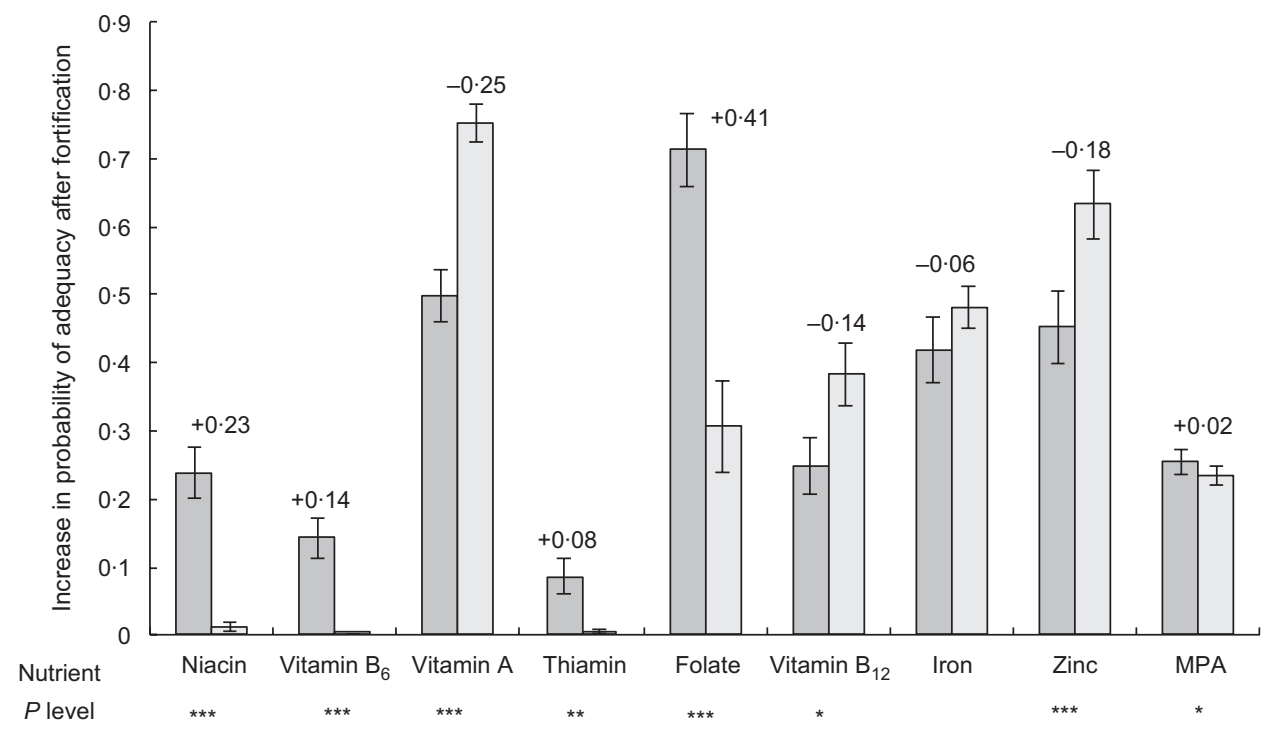

Fig. 4 Comparison of the difference in probability of adequacy (PA) with and without fortification, between pregnant women and male household heads. Values given above the bars for women represent the difference between pregnant women's and men's increase in PA after fortification of rice. $P$ values for tests of differences in the increase in PA between pregnant women and men are provided below each nutrient name, where ${ }^{*} P<0.05,{ }^{* \star} P<0.01$, ${ }^{* \star *} P<0.001$. $\square$, women; $\square$, men. MPA, mean probability of adequacy

Table 4 Regional comparisons of the difference in women's mean probability of adequacy, with and without fortification $(n 5443)^{\star}$

\begin{tabular}{|c|c|c|c|c|c|}
\hline & Mean & SD & $\begin{array}{c}\text { Conditional mean } \\
\text { estimates }\end{array}$ & $95 \% \mathrm{Cl}$ & $P$ \\
\hline \multicolumn{6}{|c|}{ Federal State of Nepal } \\
\hline Province 3 & 0.17 & 0.16 & & & \\
\hline Province 1 & 0.17 & 0.18 & 0.00 & $-0.05,0.05$ & 0.977 \\
\hline Province 2 & 0.11 & 0.15 & -0.06 & $-0.11,-0.01$ & 0.013 \\
\hline Province 4 & 0.13 & 0.15 & -0.04 & $-0.09,0.00$ & 0.077 \\
\hline Province 5 & 0.15 & 0.15 & -0.02 & $-0.09,0.05$ & 0.575 \\
\hline Province 6 & 0.21 & 0.15 & 0.04 & $0.00,0.07$ & 0.068 \\
\hline Province 7 & 0.12 & 0.17 & -0.05 & $-0.12,0.02$ & 0.127 \\
\hline \multicolumn{6}{|l|}{ Ecological zone } \\
\hline Terai & $0 \cdot 11$ & 0.15 & & & \\
\hline Hill & 0.19 & 0.17 & 0.08 & $0.05,0.10$ & $<0.001$ \\
\hline Mountain & 0.19 & 0.16 & 0.07 & $0.01,0.14$ & 0.019 \\
\hline \multicolumn{6}{|c|}{ Social safety net areas } \\
\hline Non-NFC & 0.14 & 0.16 & & & \\
\hline NFC district & 0.20 & 0.17 & 0.05 & $0.01,0.10$ & 0.012 \\
\hline \multicolumn{6}{|l|}{ Rural/urban } \\
\hline Urban & 0.18 & 0.19 & & & \\
\hline Rural & 0.13 & 0.15 & -0.05 & $-0.09,-0.01$ & 0.011 \\
\hline
\end{tabular}

NFC, Nepal Food Corporation.

${ }^{\star}$ Fortification using World Food Programme specifications using the third Nepal Annual Household Survey data.

consumption of fortified rice is wide-ranging and includes: improved $\mathrm{Fe}^{(25)}, \mathrm{Zn}^{(78)}$, vitamin $\mathrm{B}_{12}{ }^{(79)}$ and vitamin $\mathrm{A}$ status $^{(23,80)}$; lower prevalence of anaemia ${ }^{(25,26,30,81,82)}$, beriberi $^{(83)}$ and neural tube defects ${ }^{(84)}$ and improved cognition $^{(22)}$ and physical performance ${ }^{(78)}$.

\section{Implications for reaching the poorest}

Many farmers grow and consume their own rice, and it is not currently feasible to blend fortified rice kernels with home-grown rice in small-scale mills, so only rice milled commercially in large mills will be fortifiable in the foreseeable future, and only rice-buyers will benefit ${ }^{(33)}$. We found rice buyers across the wealth spectrum in urban areas (including poorer and wealthier households) and in hilly and mountainous areas with low rice production. Additional interventions are needed for households who do not buy much rice, especially in Terai areas where both home production and micronutrient deficiencies are highest ${ }^{(43)}$. 
Of those who do purchase rice, fortification may benefit better-off households most. Voluntary fortification is likely to precede or preclude mandatory fortification, and the incremental price increase will likely deter poorer buyers from choosing it ${ }^{(85)}$. Also, the private sector may prefer to fortify and market more expensive rice varieties and market its higher nutritional value, which would only be afforded by better-off consumers. One potential means by which rice fortification can benefit those who need it most will be to distribute fortified rice via social safety nets ${ }^{(85)}$ as per the Government of Nepal's plan. If subsidised fortified rice is distributed through the NFC, it could reach the most food-insecure and inaccessible areas of the country. However, to reach the poorest elsewhere, wider access to low-cost or subsidised fortified rice will be needed.

We examine the potential for rice fortification to be a gender-sensitive intervention. We find that pregnant women in province 2 are likely to see bigger improvements in their micronutrient adequacy from rice fortification than men, which could help address the gender gap in micronutrient adequacy. This may be because women tend to rely heavily on rice to meet their dietary needs ${ }^{(8,9,11)}$, and their diets comprise a higher share of starchy staples than men's ${ }^{(39)}$, but also their diets are more deficient, so gains are easier to achieve. Of course, rice fortification is not a replacement for women's empowerment or behaviour change interventions aiming to improve women's dietary quality and equity of nutrient intake within households, but it would complement such interventions.

\section{Study limitations}

Limitations of our study include extrapolation to the entire population, whereas in the short to medium term, only a small proportion of the population who purchase NFC social safety net rice and WFP school meals programme recipients would actually benefit. To realise predicted benefits, households would need all their purchased rice to be fortified. Families are likely to substitute unfortified home-grown rice with bought, fortified rice when their grown rice has run out. This means there may be benefits during the lean season before rice harvest but less benefit post-harvest in the winter when fruits/vegetables availability is limited at high altitudes. Having said this, the pre-harvest lean period is when additional intakes through fortification are most needed because multiple micronutrient serum concentrations (especially $\beta$-carotene, $\mathrm{B}_{6}, \mathrm{~B}_{9}$ (folate) and Fe concentrations) are notably low ${ }^{(6)}$.

In LBWSAT, the share of rice that was purchased was estimated by ranking the relative importance of purchase to meet staple food needs. Use of this rule of thumb to assume the proportion of rice purchased is a source of error that we cannot quantify. Both LBWSAT and AHS III surveys were collected over several months (June-September 2015 for LBWSAT and September 2014 to July 2015 for AHS III) but neither covered 12 months. This means that seasonal variation outside the periods sampled is not accounted for in our findings.

We have estimated mean intakes for men, non-pregnant women and children in the AHS III using AME to allocate nutrients to household members as per energy requirements. The assumption that women are not pregnant is important because Bland-Altman limits of agreement show that AME overestimate the intakes of pregnant women in particular. The AHS III dataset was missing eggs and green leafy vegetables, and a relatively short list of sixty foods were reported, so adequacy may be underestimated. However, conservative sensitivity analyses, and comparison with LBWSAT results, show the same key trends: adequacy of diets drastically improves with fortification but vitamin $\mathrm{B}_{12}$ (and $\mathrm{Fe}$ for pregnant women) remains problem nutrients, and MPA is constrained by unfortified nutrients such as riboflavin $\left(\mathrm{B}_{2}\right)$, Ca and vitamin $\mathrm{C}$.

Our estimates are based upon uncooked rice nutrient values which have not been adjusted for losses during cooking. Hence, there is some risk of overestimating intakes of vitamins $B_{1}, B_{2}$ and to a lesser extent $B_{9}$. However, our intake estimates from uncooked rice from are very similar to those from a slightly larger LBWSAT sample which used cooked rice values ${ }^{(39)}$, indicating that the error introduced from using uncooked rice is small.

The LBWSAT dietary adequacy estimates for pregnant women and their families may not be generalisable to more wealthy and non-plains populations of Nepal, since Dhanusha and Mahottari districts fall are relatively poor and inequitable intra-household food allocation is particularly prevalent ${ }^{(8,39)}$. On the other hand, since the AHS III is a nationally representative survey, the findings from the current study are generalisable to $\mathrm{Nepal}^{(42)}$. This means that the risk of exceeding UL is low even in wealthier households, except for Fe in scenarios where all rice consumed is fortified, pregnant women take daily Fe supplements and there is high contamination of ground water with Fe.

Future research documenting individual dietary data from different age-sex groups across Nepal would help obtain a more precise estimate of the broader potential impact on nutritional adequacy. Our results are from modelled scenarios, based on assumptions about consumption levels, requirements (infection, activity levels, nutrient retention) and interactions between nutrients. Further research to measure these could inform future models and improve their accuracy. Rather than conducting more trials under experimental conditions, we recommend careful evaluation of rice fortification through NFC and/or the School Meals Programme in Nepal, particularly effects on uptake by the private sector, wider dietary changes, biochemical indicators of micronutrient levels (especially niacin), children's health and school performance.

We conclude that fortification of rice using the WFP specification, in combination with other health and nutrition programmes, presents an opportunity to contribute 
to the reduction of micronutrient deficiencies and also to reduce inequalities in micronutrient allocation in Nepal.

\section{Acknowledgements}

Acknowledgements: We thank Saskia de Pee and Britta Schumacher from WFP for comments on the manuscript. We thank Nepal Central Bureau of Statistics for access to the Annual Household Survey 2014/15 dataset. The authors acknowledge valuable inputs during dietary data collection in the LBWSAT from Puskar Paudel, Niva Shrestha, Tom Harrison, B. James Beard, Bhim Shrestha, Sonali Jha, Anjana Rai, Anthony Costello, Sarah Style, Jayne Harthan and Lu Gram. Special thanks to project supervisors: Devlal Bishwakarma, Shankar Kaphle, Suresh Mandal and Dharambir Pasman, as well as the families who gave their time to participate in the current research. Financial support: Analyses were funded by UN WFP, Nepal. Primary data collection was funded by Child Health Research Appeal Trust and UK Department for International Development grant no. PO 5675. Some work for the current study was done at Great Ormond Street Hospital and the University College London (UCL) Great Ormond Street Institute of Child Health, which received funding from the UK Department of Health's National Institute for Health Research (NIHR) Biomedical Research Centres funding scheme. Partial funding of author N.M.S. during the data collection period was funded by Wellcome Trust Strategic Award for the Population Science of Maternal and Newborn Survival, grantno. 085417MA/Z/08/Z. Partial funding of author H.A.H.-F. during the write-up period was funded by a Sir Henry Wellcome Fellowship, grant no. 210894/Z/18/Z. N.S., H.A.H.-F. and M.M. were employed as consultants by WFP during the analysis and writing of the current article but no otherwise no donors were involved. Conflict of interest: N.M.S., H.A.H.-F. and M.M. were employed as consultants by WFP, Nepal during the analyses and write-up of the current work, but not during data collection. Aside from funding the author salaries and two WFP nutritionists reviewing the manuscript, WFP had no other role in the study. Authorship: N.M.S. conceived the study, wrote the paper, processed the AHS III data ready for analysis and had primary responsibility for the final content. H.A.H.-F. led on primary collection of dietary intake data from LBWSAT and analysed both datasets. N.M.S., H.A.H.-F. and M.M. designed the secondary analyses used in the current study while N.M.S., H.A.H.-F. and D.S.M. designed the primary research study (LBWSAT) in which the dietary research was embedded. D.S.M. oversaw management of all LBWSAT field activities. All authors read and approved the final manuscript. Ethics of human subjectparticipation: The current study was conducted according to the guidelines laid down in the Declaration of Helsinki, and all procedures involving research study participants during the parent study (LBWSAT) received ethical approval from the Nepal Health Research Council (108/2012) and the University College London Ethical Review Committee (4198/001). Written informed consent was obtained from all subjects. Ethical approval for the secondary analyses conducted here was provided by the Nepal Health Research Council (539/2018).

\section{Supplementary material}

For supplementary material accompanying this paper visit https://doi.org/10.1017/S1368980020001020

\section{References}

1. Torheim LE, Ferguson EL, Penrose K et al. (2010) Women in resource-poor settings are at risk of inadequate intakes of multiple micronutrients. J Nutr 140, 2051S-2058S.

2. Rao S, Yajnik CS, Kanade A et al. (2001) Intake of micronutrient-rich foods in rural Indian mothers is associated with the size of their babies at birth: Pune Maternal Nutrition Study. J Nutr 131, 1217-1224.

3. Zerfu TA, Umeta M \& Baye K (2016) Dietary diversity during pregnancy is associated with reduced risk of maternal anemia, preterm delivery, and low birth weight in a prospective cohort study in rural Ethiopia. Am J Clin Nutr 103, 14821484.

4. Development Initiatives (2018) 2018 Global Nutrition Report: Shining A Light to Spur Action on Nutrition. Bristol, UK: Development Initiatives.

5. Kassebaum NJ, Jasrasaria R, Naghavi M et al. (2014) A systematic analysis of global anemia burden from 1990 to 2010. Blood 123, 615-624.

6. Jiang TN, Christian P, Khatry SK et al. (2005) Micronutrient deficiencies in early pregnancy are common, concurrent, and vary by season among rural Nepali pregnant women. J Nutr 135, 1106-1112.

7. Ministry of Health and Population N, New ERA, United Nations International Children's Emergency Fund, et al. (2018) Nepal National Micronutrient Status Survey, 2016. Kathmandu, Nepal: Ministry of Health and Population, Nepal.

8. Sudo N, Sekiyama M, Maharjan M et al. (2006) Gender differences in dietary intake among adults of Hindu communities in lowland Nepal: assessment of portion sizes and food consumption frequencies. Eur J Clin Nutr 60, 469-477.

9. Henjum S, Torheim LE, Thorne-Lyman AL et al. (2015) Low dietary diversity and micronutrient adequacy among lactating women in a peri-urban area of Nepal. Public Health Nutr 18, 3201-3210.

10. Geniez P, Mathiassen A, de Pee S et al. (2014) Integrating food poverty and minimum cost diet methods into a single framework: a case study using a Nepalese household expenditure survey. Food Nutr Bull 35, 151-159.

11. Parajuli RP, Umezaki M \& Watanabe C (2012) Diet among people in the Terai region of Nepal, an area of micronutrient deficiency. J Biosoc Sci 44, 401-415.

12. Ferguson EL, Watson L, Berger J et al. (2019) Realistic foodbased approaches alone may not ensure dietary adequacy for women and young children in South-East Asia. Matern Child Health J 23, 55-66.

13. Akhter N, Saville N, Shrestha B et al. (2018) Change in cost and affordability of a typical and nutritionally adequate diet 
among socio-economic groups in rural Nepal after the 2008 food price crisis. Food Secur 10, 615-629.

14. Biehl E, Klemm RDW, Manohar S et al. (2016) What does it cost to improve household diets in Nepal? Using the cost of the diet method to model lowest cost dietary changes. Food Nutr Bull 37, 247-260.

15. Peña-Rosas JP, Mithra P, Unnikrishnan B et al. (2019) Fortification of rice with vitamins and minerals for addressing micronutrient malnutrition. Cochrane Database Syst Rev 2019(10), 1-132.

16. Muthayya S, Hall J, Bagriansky J et al. (2012) Rice fortification: an emerging opportunity to contribute to the elimination of vitamin and mineral deficiency worldwide. Food Nutr Bull 33, 296-307.

17. De-Regil LM, Pena-Rosas JP, Laillou A et al. (2014) Considerations for rice fortification in public health: conclusions of a technical consultation. Ann N Y Acad Sci 1324, $1-6$.

18. World Health Organization (2018) Guideline: fortification of Rice with Vitamins and Minerals as a Public Health Strategy. No. 9241550295. Geneva: WHO.

19. Sight and Life, World Food Programme (2015) Scaling up Rice Fortification in Asia, pp. 1-92 [K Codling, C Fabrizio, K Ghoos et al., editors]. Basel, Switzerland: Sight and Life; WFP.

20. Sambour J (2010) Introducing Fortified Rice in Cambodia and Vietnam: PATH Fortified Rice Feasibility Study, pp. 1-44. Seattle: PATH.

21. Ebbing H, Rosenzweig J \& Karim R (2015) Case study: Bangladesh. In Scaling Up Rice Fortification in Asia, pp. 79-82 [K Codling, C Fabrizio, K Ghoos et al., editors]. Basel, Switzerland: Sight and Life; WFP.

22. Fiorentino M, Perignon M, Kuong K et al. (2018) Effect of multi-micronutrient-fortified rice on cognitive performance depends on premix composition and cognitive function tested: results of an effectiveness study in Cambodian schoolchildren. Public Health Nutr 21, 816-827.

23. Perignon M, Fiorentino M, Kuong K et al. (2015) Multimicronutrient fortified rice improved vitamin a status of Cambodian school children. Eur J Nutr Food Safety 5, 832-833.

24. Perignon M, Fiorentino M, Kuong K et al. (2016) Impact of multi-micronutrient fortified rice on hemoglobin, iron and vitamin a status of Cambodian schoolchildren: a doubleblind cluster-randomized controlled trial. Nutrients $\mathbf{8}, 29-44$.

25. Moretti D, Zimmermann MB, Muthayya S et al. (2006) Extruded rice fortified with micronized ground ferric pyrophosphate reduces iron deficiency in Indian schoolchildren: a double-blind randomized controlled trial. Am J Clin Nutr 84, 822-829.

26. Radhika MS, Nair KM, Kumar RH et al. (2011) Micronized ferric pyrophosphate supplied through extruded rice kernels improves body iron stores in children: a doubleblind, randomized, placebo-controlled midday meal feeding trial in Indian schoolchildren. Am J Clin Nutr 94, 1202-1210.

27. World Food Programme \& Government of India (2017) $A$ Case for Fortified Rice in Odisha, India, pp. 1-33. New Delhi, India: WFP India.

28. Della Lucia C, Rodrigues K, Rodrigues V et al. (2016) Diet quality and adequacy of nutrients in preschool children: should rice fortified with micronutrients be included in school meals? Nutrients $\mathbf{8}, 296$.

29. Beinner MA, Velasquez-Meléndez G, Pessoa MC et al. (2010) Iron-fortified rice is as efficacious as supplemental iron drops in infants and young children. J Nutr 140, 49-53.

30. Angeles-Agdeppa I, Capanzana MV, Barba CV et al. (2008) Efficacy of iron-fortified rice in reducing anemia among schoolchildren in the Philippines. Int J Vitam Nutr Res $\mathbf{7 8}$, 74-86.
31. Hotz C, Porcayo M, Onofre G et al. (2008) Efficacy of ironfortified ultra rice in improving the iron status of women in Mexico. Food Nutr Bull 29, 140-149.

32. Tacsan L, Fabrizio C \& Smit J (2015) Rice fortification in Costa Rica: case study. In Scaling Up Rice Fortifiction in Asia, pp. 73-78 [K Codling, C Fabrizio, K Ghoos et al., editors]. Basel, Switzerland: Sight and Life; WFP.

33. World Food Programme \& Government of Nepal (2018) Landscape Analysis for Rice Fortification in Nepal. Kathmandu, Nepal: WFP and Government of Nepal.

34. Global Alliance for Improved Nutrition (2017) Fortification Assessment Coverage Toolkit (FACT) Survey in Afghanistan. Geneva, Switzerland: Global Alliance for Improved Nutrition.

35. Harris-Fry H, Beard BJ, Harrisson T et al. (2018) Smartphone tool to collect repeated $24 \mathrm{~h}$ dietary recall data in Nepal. Public Health Nutr 21, 260-272.

36. Harris-Fry H, Paudel P, Karn M et al. (2016) Development and validation of a photographic food atlas for portion size assessment in the southern plains of Nepal. Public Health Nutr 19, 2495-2507.

37. Harris-Fry HA (2016) Intra-household food allocation in rural Nepal. PhD Thesis, University College London.

38. Harris-Fry HA, Paudel P, Harrisson T et al. (2018) Participatory women's groups with cash transfers can increase dietary diversity and micronutrient adequacy during pregnancy, whereas women's groups with food transfers can increase equity in intrahousehold energy allocation. J Nutr 148, 1472-1483.

39. Harris-Fry HA, Paudel P, Shrestha N et al. (2018) Status and determinants of intra-household food allocation in rural Nepal. Eur J Clin Nutr 72, 1524-1536.

40. Saville NM, Shrestha BP, Style S et al. (2016) Protocol of the Low Birth Weight South Asia Trial (LBWSAT), a cluster-randomised controlled trial testing impact on birth weight and infant nutrition of Participatory Learning and Action through women's groups, with and without unconditional transfers of fortified food or cash during pregnancy in Nepal. BMC Pregnancy Childb 16, 320.

41. Saville NM, Shrestha BP, Style S et al. (2018) Impact on birth weight and child growth of Participatory Learning and Action women's groups with and without transfers of food or cash during pregnancy: findings of the low birth weight South Asia cluster-randomised controlled trial (LBWSAT) in Nepal. PLOS ONE 13, e0194064.

42. Central Bureau of Statistics (2016) Annual Household Survey 2014/15. Kathmandu, Nepal: Central Bureau of Statistics, Nepal and UNDP.

43. Ministry of Health, Nepal, New ERA \& ICF (2017) Nepal Demographic and Health Survey 2016, pp. 1-591. Kathmandu, Nepal: Ministry of Health, Nepal.

44. Style S, Beard BJ, Harris-Fry H et al. (2017) Experiences in running a complex electronic data capture system using mobile phones in a large-scale population trial in southern Nepal. Global Health Action 10, 1330858.

45. Weisell R \& Dop MC (2012) The adult male equivalent concept and its application to Household Consumption and Expenditures Surveys (HCES). Food Nutr Bull 33, S157-S162.

46. de Pee S (2014) Proposing nutrients and nutrient levels for rice fortification. Ann N Y Acad Sci 1324, 55-66.

47. World Food Programme (2016) Technical specifications for Rice - fortified. https://documents.wfp.org/stellent/groups/ public/documents/manual_guide_proced/wfp283518.pdf (accessed July 2018).

48. Bangladesh Standards and Testing Institution (2015) Bangladesh Standard Specification for Fortified Rice. Dhaka, Bangladesh.

49. de Pee S, Moretti D \& Fabrizio C (2018) Standards and specifications for fortified rice. In Scaling Up Rice Fortification in West Africa, pp. 63-67 [K Codling, C Fabrizio, K Ghoos et al., editors]. Basel, Switzerland: Sight and Life and WFP. 
50. Bienvenido OJ \& Food and Agriculture Organization (1993) Rice in Human Nutrition. FAO Food and Nutrition Series no 26. pp. 1-162. Rome, Italy: International Rice Research Institute and UN Food and Agriculture Organisation (FAO).

51. Department of Food Technology and Quality Control (DFTQC) Nepal (2017) Nepalese Food Composition Table, 3rd ed., pp. 1-77. Kathmandu, Nepal: DFTQC.

52. Longvah T, Anantan I, Bhaskarachary K et al. (2017) Indian Food Composition Tables. National Institute of Nutrition, Indian Council of Medical Research Hyderabad.

53. Shaheen N, Bari L \& Mannan M (2013) Food composition table for Bangladesh. University of Dhaka.

54. Montville JB, Ahuja JK, Martin CL et al. (2013) USDA food and nutrient database for dietary studies (FNDDS), 5.0. Procedia Food Sci 2, 99-112.

55. National Research Council (1986) The Probability Approach. Washington, DC: National Academies Press.

56. Box G \& Cox D (1964) An analysis of transformations. JR Stat Soc Series B (Methodol) 26, 211-243.

57. Food and Agriculture Organization \& World Health Organization (2004) Vitamin and Mineral Requirements in Human Nutrition. Report of a joint FAO/WHO expert consultation, Bangkok, Thailand, 21-30 September 1998.

58. Food and Nutrition Board, Committee to Review Dietary Reference Intakes for Vitamin D and Calcium Institute of Medicine (2011) Dietary Reference Intakes for Calcium and Vitamin D. Washington, DC: National Academies Press.

59. Food and Nutrition Board \& Institute of Medicine (2001) Dietary Reference Intakes for Vitamin A, Vitamin K, Arsenic, Boron, Chromium, Copper, Iodine, Iron, Manganese, Molybdenum, Nickel, Silicon, Vanadium, and Zinc. A Report of the Panel on Micronutrients, Subcommittees on Upper Reference Levels of Nutrients and of Interpretation and Uses of Dietary Reference Intakes, and the Standing Committee on the Scientific Evaluation of Dietary Reference Intakes. Washington, DC: National Academies Press.

60. Brown KH, Rivera JA, Bhutta $\mathrm{Z}$ et al. (2004) International Zinc Nutrition Consultative Group (IZiNCG) technical document. Assessment of the risk of zinc deficiency in populations and options for its control. Food Nutr Bull 25, S99-203.

61. Hotz C (2007) Dietary indicators for assessing the adequacy of population zinc intakes. Food Nutr Bull 28, S430-S453.

62. World Health Organization (WHO) (2006) Guidelines on Food Fortification with Micronutrients [L Allen, B de Benoist, O Dary et al., editors]. Geneva, Switzerland: WHO and $\mathrm{FAO}$.

63. Montgomery S, Rosenweig J \& Smit J (2015) Technology for rice fortification. In Scaling Up Rice Fortification in Asia, pp. 57-62 [K Codling, C Fabrizio, K Ghoos et al., editors]. Basel, Switzerland: Sight and Life; WFP.

64. Bland JM \& Altman DG (1986) Statistical methods for assessing agreement between two methods of clinical measurement. Lancet 8476, 307-310.

65. Tang AM, Chung M, Dong K et al. (2016) Determining a Global Mid-Upper Arm Circumference Cutoff to Assess Malnutrition in Pregnant Women. Washington DC, USA: Family Health International (FHI) 360/Food and Nutrition Technical Assistance III Project (FANTA).

66. Tang AM, Chung M, Dong K et al. (2017) Determining a Global Mid-Upper Arm Circumference Cutoff to Assess Underweight in Adults (Men and Nonpregnant Women). Washington, DC: FHI 360/FANTA.

67. Food and Agriculture Organization \& Family Health International (FHI) 360 (2016) Minimum Dietary Diversity for Women: A Guide for Measurement. Rome: FAO.
68. Mahato S, Mahato A, Karna PK et al. (2018) Investigating aquifer contamination and groundwater quality in eastern Terai region of Nepal. BMC Res Notes 11, 321.

69. Pant BR (2011) Ground water quality in the Kathmandu valley of Nepal. Environ Monit Assess 178, 477-485.

70. Kannel PR, Lee S \& Lee Y-S (2008) Assessment of spatialtemporal patterns of surface and ground water qualities and factors influencing management strategy of groundwater system in an urban river corridor of Nepal.J Environ Manage 86, 595-604.

71. Pokhrel D, Bhandari B \& Viraraghavan T (2009) Arsenic contamination of groundwater in the Terai region of Nepal: an overview of health concerns and treatment options. Environ Int 35, 157-161.

72. World Health Organization (2008) Guidelines for DrinkingWater Quality: Incorporating the First and Second Addenda. Geneva: WHO.

73. Merrill RD, Shamim AA, Ali $\mathrm{H}$ et al. (2011) Iron status of women is associated with the iron concentration of potable groundwater in rural Bangladesh. J Nutr 141, 944-949.

74. de Gier B, Ponce MC, Perignon M et al. (2016) Micronutrientfortified rice can increase hookworm infection risk: a cluster randomized trial. PLOS ONE 11, e0145351.

75. Arsenault JE, Yakes EA, Islam MM et al. (2013) Very low adequacy of micronutrient intakes by young children and women in rural Bangladesh is primarily explained by low food intake and limited diversity. J Nutr 143, 197-203.

76. Allen RE, Dangour AD, Tedstone AE et al. (2015) Does fortification of staple foods improve vitamin D intakes and status of groups at risk of deficiency? A United Kingdom modeling study. Am J Clin Nutr 102, 338-344.

77. Laillou A, Berger J, Le BM et al. (2012) Improvement of the Vietnamese diet for women of reproductive age by micronutrient fortification of staples foods and condiments. PLOS ONE 7, e50538.

78. Pinkaew S, Winichagoon P, Hurrell RF et al. (2013) Extruded rice grains fortified with zinc, iron, and vitamin A increase zinc status of Thai school children when incorporated into a school lunch program. J Nutr 143, 362-368.

79. Thankachan P, Rah JH, Thomas $\mathrm{T}$ et al. (2012) Multiple micronutrient-fortified rice affects physical performance and plasma vitamin B-12 and homocysteine concentrations of Indian school children. $J$ Nutr 142, 846-852.

80. Hussain SZ, Singh B \& Rather AH (2014) Efficacy of micronutrient fortified extruded rice in improving the iron and vitamin A status in Indian schoolchildren. Int J Agr Food Sci Technol 3, 227-238.

81. World Food Programme \& Government of India (2017) $A$ Case for Fortified Rice in Odisha, pp. 1-33. New Delhi, India: WFP India.

82. Khan SY (2017) Fortifying school meals: Rice fortification to address anaemia in Odisha. Nutr Exchange 7, 22.

83. Salcedo J Jr, Bamba M, Carrasco EO et al. (1950) Artificial enrichment of white rice as a solution to Endemic Beriberi: report of field trials in Bataan, Philippines, three figures. J Nutr 42, 501-523.

84. Argüello B, de la Paz M \& Umaña Solís LM (2011) Impacto de la fortificación de alimentos con ácido fólico en los defectos del tubo neural en Costa Rica [Impact of the fortification of food with folic acid on neural tube defects in Costa Rica]. Rev Panam Salud Pública 30, 1-6.

85. Codling K, Fabrizio C \& Rosenzweig J (2018) Identifying appropriate delivery options for fortified rice. In Scaling Up Rice Fortification in Asia [K Codling, C Fabrizio, K Ghoos et al., editors]. Basel, Switzerland: Sight and Life; WFP. 